\title{
ARTERIAL TO END-TIDAL CARBON DIOXIDE TENSION DIFFERENCE IN CHILDREN UNDER HALOTHANE ANAESTHESIA
}

\author{
Niels Valentin, Bjarne Lomholt and Maja Thorup
}

\begin{abstract}
Using blood gas determinations and capnography, the relationship between arterial and end-tidal $\mathrm{PCO}_{2}$ was investigated in 20 children under halothane anaesthesia with spontaneous respiration. A median arterial to end-tidal carbon dioxide tension difference of $0.66 \mathrm{kPa}(5 \mathrm{~mm} \mathrm{Hg})$ was found. There was a close correlation between $\mathrm{Pa}_{\mathrm{CO}_{2}}$ and the magnitude of the carbon dioxide difference. Our findings may largely be explained by an increase in $\mathrm{VD} / \mathrm{VT}$ (presumably mainly due to a reduction of $\mathrm{VT}$ ) causing admixture of dead space air throughout expiration. It is concluded that though end-tidal carbon dioxide does not exactly reflect $\mathrm{Pa}_{\mathrm{CO}_{2}}$ capnography may be of value as a monitor of respiration in paediatric anaesthesia at normal or near-normal values of end-tidal carbon dioxide.
\end{abstract}

Key Words: Anaesthesia, paediatric; Carbon Dioxide Tension, arterial, end-tidal.

WHENEVER POSSIBLE non-invasive monitoring methods should be preferred to invasive techniques. After the advent of handy easily operated apparatus, capnography seemed to be an attractive alternative to arterial cannulation or repeated arterial punctures for respiratory monitoring in children during anaesthesia.

Identical results, or at least a close and predictable relationship between the results obtained by the two methods are a condition for replacing one method with the other. Authors investigating anaesthetized adult patients ${ }^{1,2}$ have described an arterial to end-tidal carbon dioxide tension gradient. In the study by Nunn and $\mathrm{Hill}^{2}$ the gradient was $5 \mathrm{~mm} \mathrm{Hg}(0-10)$ and unrelated to the level of $\mathrm{Pa}_{\mathrm{CO}_{2}}$. The gradient was the same during spontaneous and controlled ventilation.

To our knowledge the phenomenon has not been studied in children, and the present study was undertaken to investigate the value of capnography as a respiratory monitor during anaesthesia in children.

\section{Material and Methods}

The material comprised 20 children undergoing tonsillectomy or adenotonsillectomy. The

Niels Valentin, M.D., Assistant Professor; Bjarne Lomholt, M.D., Senior Registrar; Maja Thorup, M.D., Registrar; Department of Anaesthesia, Gentofte Hospital, DK 2900 Hellerup, Denmark.

Can. Anaesth. Soc. J., vol. 29, no. 1, January 1982 median age was five years (range 3-10 years) and the median weight $20 \mathrm{~kg}$ (range $15-29 \mathrm{~kg}$ ). All patients were otherwise healthy.

Premedication was diazepam (Apozepam(8)) $0.75 \mathrm{mg} \cdot \mathrm{kg}^{-1}$ (maximum dose $20 \mathrm{mg}$ ) given rectally 30 minutes before anaesthesia.

Anaesthesia was induced with halothane in nitrous oxide and oxygen $(2: 1)$ on a Bain system with spontaneous respiration. Fresh gas flow was $200 \mathrm{ml} \cdot \mathrm{kg}^{-1}$ in children weighing $15-20 \mathrm{~kg}$ and $150 \mathrm{ml} \cdot \mathrm{kg}^{-1}$ in children weighing $20-30 \mathrm{~kg}$. The calculated values were rounded upwards to the nearest litre or half litre. After about five minutes on three per cent halothane orotracheal intubation was done without the use of muscle relaxants and anaesthesia was maintained with halothane, nitrous oxide and oxygen on spontaneous respiration. The concentration of halothane necessary to provide a clinically sufficient level of anaesthesia under the conditions described was about two per cent.

After intubation, respiration was monitored continuously using a Datex CD 101 infrared capnograph. The test gas was sampled close to the tracheal tube at a rate of $400 \mathrm{ml} \cdot \mathrm{min}^{-1}$ and was returned to the anaesthetic circuit after analysis (Figure 1). The capnograph was calibrated against a gas containing 7.08 per cent carbon dioxide. Twenty minutes after the induction of anaesthesia, an arterial sample was taken for duplicate blood gas analysis using Radiometer ABL2 equipment with automatic calibration. 


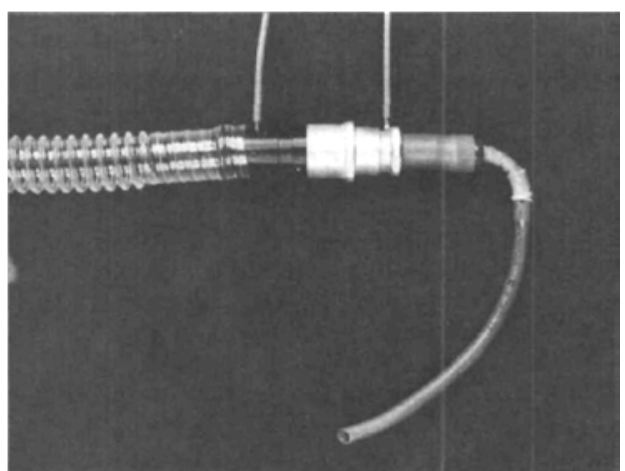

Figure 1. Arrangement for gas sampling. The test gas is sampled through the tubing nearest to the tracheal tube and returned to the circuit through the other (left) narrow tubing.

During blood sampling three consecutive readings of end-tidal carbon dioxide were taken. The mean of these readings was recalculated to carbon dioxide tension for comparison with $\mathrm{Pa}_{\mathrm{CO}_{2}}$. The electrocardiogram was monitored continuously.

In one case investigated after the remainder and not included in the statistical calculations we had the opportunity to obtain capnographic tracings. In that patient an additional arterial puncture was made shortly before tracheal extubation.

The Mann Whitney test was used for testing differences between the two methods of measurement. Correlation was tested by use of Spearman's rank correlation coefficient.

\section{RESULTS}

With either method of measurement elevated carbon dioxide tensions were found in most cases. With the exception of three patients, $\mathrm{Pa}_{\mathrm{CO}_{2}}$ was higher than end-tidal carbon dioxide tension, the median arterial to end-tidal carbon dioxide tension difference being $5 \mathrm{~mm} \mathrm{Hg}$ (Table). The difference between the two sets of measurements was significant at the five per cent level.

As demonstrated in Figure 2, there was a highly significant correlation between the level of $\mathrm{Pa}_{\mathrm{CO}_{2}}$ and the magnitude of the arterial to end-tidal carbon dioxide difference $\left(r_{s}=0.85\right.$, $P<0.01$ ).

\section{Discussion}

The above data clearly demonstrate that under

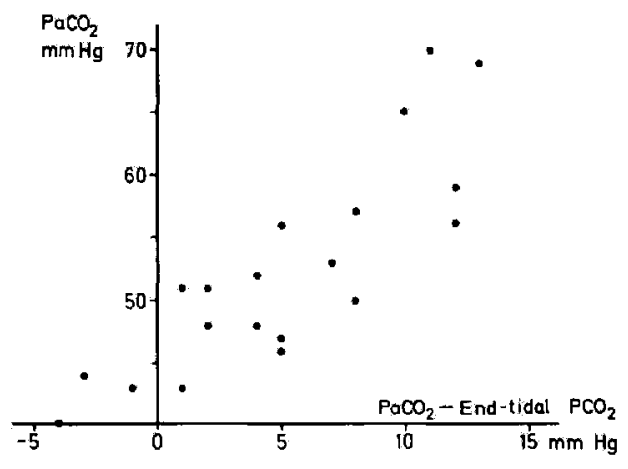

Figure 2. The arterial to end-tidal carbon dioxide tension difference during halothane anaesthesia with spontaneous respiration related to $\mathrm{Pa}_{\mathrm{CO}_{2}}$.

the conditions of our study end-tidal carbon dioxide does not completely reflect $\mathrm{Pa}_{\mathrm{CO}_{2}}$. The median difference of about $5 \mathrm{~mm} \mathrm{Hg}$ compares well with previous work in adult patients. ${ }^{1.2}$ The correlation between $\mathrm{Pa}_{\mathrm{CO}_{2}}$ and arterial to endtidal carbon dioxide is at variance with the findings of Nunn and $\mathrm{Hill}^{2}$ in adult patients. In their study the carbon dioxide tension difference was unrelated to $\mathrm{Pa}_{\mathrm{CO}_{2}}$ both during controlled and spontaneous respiration. They found that physiological dead space was a function of tidal volume and described a correlation between the fraction of gas expired from unperfused spaces and $V_{D_{(A L V)}} / V_{T}$, attributing the arterial to endtidal carbon dioxide difference to ventilation/ perfusion $(\mathbf{V} / Q)$ inequalities.

Similarly, Rose and Froese ${ }^{4}$ found that in anaesthetized ventilated children dead space varied with tidal volume, thus maintaining an almost constant $V_{\mathrm{D}} / \mathrm{V}_{\mathrm{T}}$. However, in contrast to the findings in adult patients ${ }^{2}$ they found that during spontaneous respiration dead space was largely unaffected by changes in tidal volume; that is, VD/VT was inversely related to tidal volume. A high $V_{D} / V_{T}$ leading to the admixture of dead space air throughout the expiration of a small volume of alveolar air would offer an acceptable explanation of the arterial to end-tidal carbon dioxide difference. This explanation gains support from the capnograms in Figures 3 and 4 . Figure 3 was recorded during rather deep halothane anaesthesia. Respiratory rate was 33 , $\mathrm{Pa}_{\mathrm{CO}_{2}} 8.25 \mathrm{kPa}(62 \mathrm{~mm} \mathrm{Hg})$ and arterial to endtidal carbon dioxide difference $1.06 \mathrm{kPa}$ $(8 \mathrm{~mm} \mathrm{Hg})$. The lack of a plateau-expressing the expiration of alveolar air-is evident. Figure 4 , which was recorded immediately before extubation and after the discontinuation of hal- 
TABLE

Arterial and End-Tidal $\mathrm{PCO}_{2}$ During Halothane ANaESThesia IN SPONTANEOUSLy BREATHING-ChILDREN

\begin{tabular}{lcc}
\hline \hline & Median & Range \\
\hline $\mathrm{Pa}_{\mathrm{CO}_{2}} \mathrm{kPa}(\mathrm{mmHg})$ & $6.78(51)$ & $5.32-9.31(40-70)$ \\
$\mathrm{PET}_{\mathrm{CO}_{2}} \mathrm{kPa}(\mathrm{mmHg})$ & $6.25(47)$ & $5.45-7.85(41-59)$ \\
Difference $\mathrm{kPa}(\mathrm{mmHg})$ & $+0.66(+5)$ & -0.53 to $+1.73(-4$ to +13$)$ \\
\hline
\end{tabular}

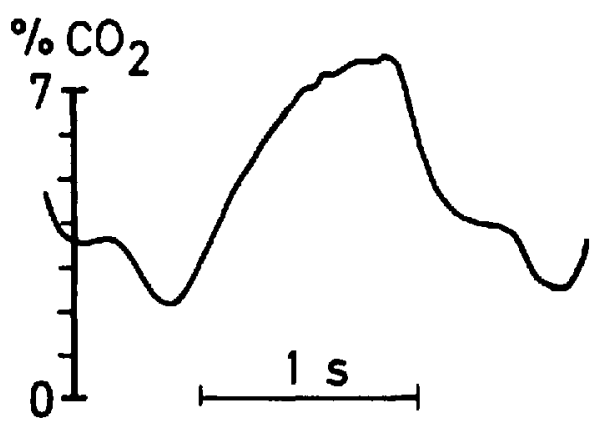

FIGURE 3. Capnogram obtained during deep halothane anaesthesia with spontaneous respiration in a four year old child.

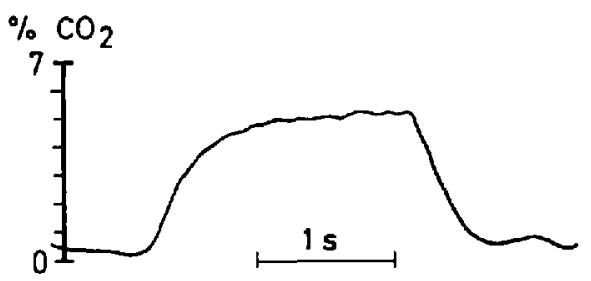

FIGURE 4. Capnogram obtained immediately before tracheal extubation. The same patient as Figure 3.

othane, is a normal capnogram with a well marked plateau. At that moment the respiratory rate was $19, \mathrm{~Pa}_{\mathrm{CO}_{2}} 5.45 \mathrm{kPa}(41 \mathrm{~mm} \mathrm{Hg})$ and the end-tidal to arterial carbon dioxide difference $0.27 \mathrm{kPa}(2 \mathrm{~mm} \mathrm{Hg})$.

The increase in $\mathrm{VD}_{\mathrm{D}} \mathrm{VT}$ responsible for the development of the arterial to end-tidal carbon dioxide difference during spontaneous respiration may be due entirely to the change in respiratory pattern seen during halothane anaesthesia. Rose and Froese 4 found that dead space was the same during halothane anaesthesia with rapid shallow respiration as it was during anaesthesia with enflurane and a narcotic, where respiration was slow and deep. Similarly, a closer analysis of the data given by Kain, Panday and Nunn ${ }^{5}$ suggests that the increases in
$\mathrm{VD} / \mathrm{VT}$ seen with deeper levels of halothane anaesthesia in adults was mainly due to reductions in alveolar ventilation whereas VD was virtually the same throughout the range of concentrations of halothane. The number of observations at each concentration of halothane was small and, in their series as well as in ours, it can not be ruled out that regional increases in $\dot{V} / Q$ (due to pulmonary hypotension) contribute to the increases in $V_{D} / V_{T}$ by increasing $V_{D}$.

The highly significant correlation between $\mathrm{Pa}_{\mathrm{CO}_{2}}$ and the magnitude of the arterial to end-tidal carbon dioxide tension difference is probably a reflection of the above-mentioned relationship: in deeper levels of halothane anaesthesia (pronounced hypercapnia) VT is smaller and $V_{D} / V_{T}$ larger than in individuals without respiratory depression.

Considering the relationship between respiratory depression and arterial to end-tidal carbon dioxide difference, capnography seems to be of little value as a measure of arterial carbon dioxide tensions in anaesthetized children. In addition, our study does not permit any conclusions concerning ventilated children. However, as the arterial to end-tidal carbon dioxide difference is small at normal or near-normal values of end-tidal carbon dioxide, we find that capnography may have a place in clinical practice and in teaching. Normal values of end-tidal carbon dioxide in a spontaneously breathing child can probably be taken as an expression of normocapnia, whereas even moderate elevations of end-tidal carbon dioxide may indicate considerable degrees of hypercapnia.

\section{REFERENCES}

1. Askrog, V.F., Pender, J.W., Smith, T.C. \& ECKENHOFF, J.E. Changes in respiratory dead space during halothane, cyclopropane, and nitrous oxide anesthesia. Anesthesiology 25: 342 (1964).

2. NunN, J.F. \& HiLl, D.W. Respiratory dead space and arterial to end-tidal $\mathrm{CO}_{2}$ tension differ- 
ence in anesthetized man. J. Appl. Physiol. 15: 383 (1960).

3. BaiN, J.A. \& Spoerel, W.E. A streamlined anesthetic system. Can. Anaesth. Soc. J. 19:426 (1972).

4. ROSE, D.K. \& Froese, A.B. Changes in respiratory pattern affect dead space/tidal volume ratio during spontaneous but not during controlled ventilation: A study in pediatric patients. Anesth. Analg. 59: 341 (1980).

5. Kain, M.L., Panday, J. \& Nunn, J.F. The effect of intubation on the deadspace during halothane anaesthesia. Brit. J. Anaesth. 41: 94 (1969).

\section{RÉsumé}

A l'aide de la gazométrie et de la capnographie, on a étudié le rapport $\mathrm{PCO}_{2}$ artérielle et la $\mathrm{PCO}_{2}$ mesurée en fin d'expiration sur vingt enfants anesthésiés à l'halothane en respiration spontanée. La médiane de la différence entre la $\mathrm{PCO}_{2}$ de fin d'expiration et la $\mathrm{Pa}_{\mathrm{CO}_{2}}$ a été établie à $0.66 \mathrm{kPa}(5 \mathrm{mmHg})$. On a trouvé une corrélation étroite entre la $\mathrm{Pa}_{\mathrm{CO}_{2}}$ et l'importance de cette différence. Nos résultats peuvent s'expliquer par une augmentation du Vo/VT (présumément due en grande partie a une baisse du VT) causant une contamination plus grande de l'air expiré par l'espace mort. 